\title{
An Amperometric Biosensor Based on Ascorbate Oxidase Immobilized in Poly(3,4-ethylenedioxythiophene)/Multi-Walled Carbon Nanotubes Composite Films for the Determination of L-Ascorbic Acid
}

\author{
Ming LIU, $* * *$ Yangping Wen, ${ }^{*}, * *$ Jingkun Xu, ${ }^{* \dagger}$ Haohua He, ${ }^{* * \dagger}$ Dong LI, ${ }^{*}, * *$ Ruirui YuE, ${ }^{*}$ and \\ Guodong LiU $* * *$ \\ *Jiangxi Key Laboratory of Organic Chemistry, Jiangxi Science and Technology Normal University, \\ Nanchang 330013, China \\ **Key Laboratory of Crop Physiology, Ecology and Genetic Breeding, Ministry of Education, Key Laboratory of \\ Physiology, Ecology and Cultivation of Double Cropping Rice, Ministry of Agriculture, Jiangxi Agricultural \\ University, Nanchang 330045, China \\ ***School of Communication and Electronics, Jiangxi Science and Technology Normal University, \\ Nanchang 330013, China
}

\begin{abstract}
An amperometric L-ascorbic acid (AA) biosensor fabricated by immobilizing ascorbate oxidase (AO) in poly(3,4-ethylenedioxythiophene) (PEDOT) and multi-walled carbon nanotubes (MWCNTs) composite films was reported for the first time. The entrapment of AO in PEDOT/MWCNTs composite films was performed during an electrochemical polymerization process. The influence of various experimental conditions was examined for determining the optimum analytical performance. The response of the biosensor towards AA under the optimized conditions is linear from 0.05 to $20 \mathrm{mM}$ with a detection limit of $15 \mu \mathrm{M}(S / N=3)$. The biosensor shows a response time of $20 \mathrm{~s}$ and a sensitivity of $23.95 \mathrm{~mA} \mathrm{M}^{-1} \mathrm{~cm}^{-2}$. The apparent Michaelis-Menten constant $\left(K_{\mathrm{m}}\right)$ and apparent activation energy $\left(E_{\mathrm{a}}\right)$ are $19.5 \mathrm{mM}$ and $21 \mathrm{~kJ} \mathrm{~mol}^{-1}$, respectively. Moreover, the biosensor exhibits good anti-interferent ability, good reproducibility and remarkable storage stability.
\end{abstract}

(Received December 23, 2010; Accepted March 7, 2011; Published May 10, 2011)

L-Ascorbic acid (vitamin C, AA), a natural water-soluble vitamin, is a potent reducing and antioxidant agent that functions in fighting bacterial infections, in detoxifying reactions, and in the formation of collagen in fibrous tissue, teeth, bones, connective tissue, skin, and capillaries. Found in citrus and other fruits, and in vegetables, AA cannot be produced or stored by humans, and must be obtained in the diet. It is thus very important to develop quick and effective methods for the quantitative detection of AA in fruits, vegetables, grain crops, agro-food products and beverages. Some methods have been available for AA detection, such as chromatographic methods ${ }^{1,2}$ and spectrophotometric methods.,4 Nevertheless, complex sample pretreatment procedures, time-consuming manipulations and low sensitivities limit their practical applications. Electrochemical methods ${ }^{5-9}$ have long been used to detect AA either directly or combined with other techniques. Since development of the first amperometric enzyme-based AA biosensor, tremendous attention has been focused on improving the response performances of enzyme electrodes for biosensor research, because this class of technique is characterized by high sensitivity and selectivity, simplicity, and easy miniaturization. ${ }^{10}$

The immobilization of an enzyme on the sensing bioelement, which specifically recognizes the analyte (substrate), onto a

† To whom correspondence should be addressed. E-mail: xujingkun@tsinghua.org.cn; hhhua64@163.com transducing surface, is the keystep in constructing biosensing devices. Different configurations usually exploited for the immobilization of enzyme are adsorption, covalent binding, entrapment in gels and membranes or polymer matrices, and the cross-linking of a specific enzyme. ${ }^{11-16}$ Electropolymerization, a recent focus among immobilization strategies, is an electrochemical route to form polymeric coatings by the entrapment of biomolecules, and involves the application of an appropriate potential to a working electrode immersed in an aqueous solution containing the electropolymerizable monomer and the immobilizable biomolecule, which is homogeneously incorporated in the growing polymer. The mechanism of incorporation of biomolecules into the growing polymers, however, is not yet fully understood. ${ }^{17}$ The entrapment of enzymes in electropolymerized conducting polymeric films easily ensures proximity between the active site of the enzyme and the conducting surface. ${ }^{18-20}$ This method provides a facile and controllable way for depositing biologically active molecules of any size and geometry to defined areas on electrodes without a chemical reaction that could affect the activity of the entrapped biomolecules.

Intrinsically conducting polymers (ICPs), in particular, are especially amenable for electrochemical biosensor development for providing biomolecule immobilization. Their advantages for biosensing applications include biocompatibility, an ability to entrap and controllably release biological molecules (reversible doping), efficient charge-transfer from a biochemical reaction 
and an ability for tuning electrical, physical, chemical and optical properties in view of a particular application. ${ }^{21}$ Among ICPs, poly(3,4-ethylenedioxythiophene) (PEDOT) is a very popular material by virtue of its high conductivity, good redox reversibility and stability, as well as having an environment-friendly feature. ${ }^{22,23}$ These excellent properties of ICPs, along with the possibility to entrap enzymes during electrochemical polymerization, have been exploited for fabricating amperometric enzyme-based biosensors. Carbon nanotubes (CNTs) are certainly one of the most popular nanosupports for biomolecule immobilization, since their peculiar structures, including high porosity and reactivity, assure a large active surface area and suitability for the production of miniaturized biosensors. ${ }^{24-26}$ Recently, ICPs incorporated with CNTs have been largely prepared for the fabrication of biosensing devices. ${ }^{27-30}$ The resulting ICPs/CNTs composites have lower charge transfer resistance and mass-transfer impedance than CNTs alone, thus yielding a nanomaterial with synergic and improved properties. It is expected that the combination of ICPs with CNTs may generate composites with new and interesting properties, providing higher sensitivity and stability of the immobilized molecules, thus constituting the basis for new and improved analytical devices for biosensing and other applications.

Previously, Wen et al. in our group fabricated an amperometric AA biosensor based on ascorbate oxidase (AO) immobilized in a PEDOT matrix by a one-step electropolymerization method. The proposed biosensor could detect AA successfully, and had a good linear range. However, the biosensor suffered from bad storage stability due to easy leakage of AO from the PEDOT matrix, which limits its application as biosensor materials. ${ }^{31}$ Inspired by preceding studies, we reasoned that multi-walled carbon nanotubes (MWCNTs) could facilitate the fabrication of an amperometric biosensor with better storage stability. The primary objective of this study was to prove this hypothesis. Subsequently, an amperometric AA biosensor with better storage stability was successfully fabricated by the one-step electrochemical immobilization of AO on a PEDOT/MWCNTs composite modified platinum $(\mathrm{Pt})$ disc electrode. Besides, our work represents the first attempt to immobilize $\mathrm{AO}$ in PEDOT/MWCNTs composite films to develop an amperometric biosensor for the determination of AA.

\section{Experimental}

\section{Chemicals}

AO (1800 $\mathrm{U} \mathrm{mg}^{-1}$, EC 1.10.3.3) from cucumber (Cucurbita sp.) and MWCNTs suspension were purchased from Chengdu Institute of Organic Chemistry, Chinese Academy of Sciences (MWCNTs content, $4.39 \mathrm{wt} \%$; outer diameter, 50 - $100 \mathrm{~nm}$; length, $5-15 \mu \mathrm{m})$. EDOT (99\%; Aldrich), sodium $N$-lauroylsarcosinate (SLS, 95\%; Aldrich). Phosphate buffer solutions (PBS; $0.05 \mathrm{M}$ ) with various $\mathrm{pH}$ values were prepared with $\mathrm{Na}_{2} \mathrm{HPO}_{4}$ and $\mathrm{NaH}_{2} \mathrm{PO}_{4}$ (obtained from Sinopharm Chemical Reagent Co., Ltd.). AA was purchased from Bio Basic Inc. Lithium perchlorate trihydrate $\left(\mathrm{LiClO}_{4}\right.$; Sinopharm Chemical Reagent Co., Ltd.) of analytical reagent grade was used as received. Double-distilled deionized water was used throughout this study.

\section{Apparatus}

All electrochemical experiments were performed using a potentiostat-galvanostat (Model 263A, EG\&G Princeton Applied Research), with a conventional three-electrode cell

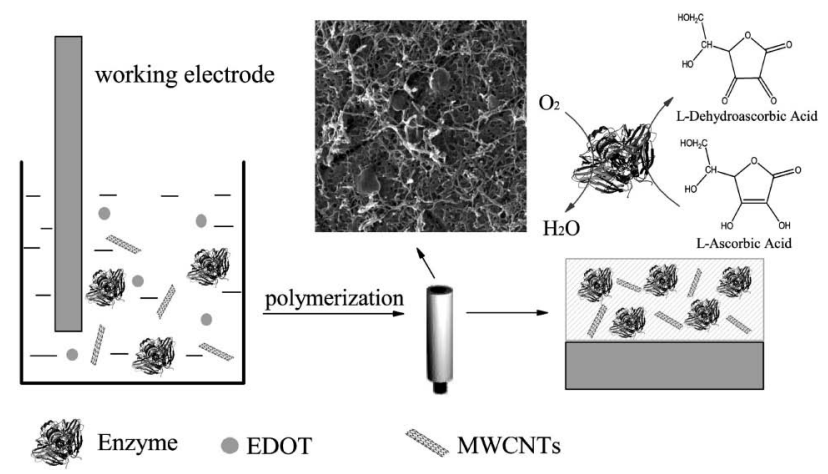

Scheme 1 Illustration of the fabrication process and the electrochemical oxidation of AA.

system, at room temperature. A 3-mm diameter Pt disc electrode was used as the working electrode, a 1-mm diameter stainless-steel wire was the auxiliary electrode and a saturated calomel electrode (SCE) was the reference electrode. The addition of the sample was carried out with a micropipettor. The $\mathrm{pH}$ value was measured with a Delta $320 \mathrm{pH}$ meter. The temperature was controlled with a type-HHS thermostat.

\section{Preparation of the PEDOT/MWCNTS/AO-modified electrode}

Before modification, a bare Pt disc electrode was carefully polished with a $0.05-\mu \mathrm{m}$ alumina slurry, then thoroughly rinsed with double-distilled deionized water, followed by ultrasonically for $5 \mathrm{~min}$, respectively.

The PEDOT/MWCNTs/AO-modified electrode was prepared by one-step potentiostatical polymerization in PBS containing $0.02 \mathrm{M}$ EDOT, $0.075 \mathrm{mg} \mathrm{mL}^{-1} \mathrm{AO}, 1 \mathrm{mg} \mathrm{mL}^{-1}$ MWCNTs, $0.02 \mathrm{M} \mathrm{SLS}$, and $0.02 \mathrm{M} \mathrm{LiClO}_{4}$ at a polymerization potential of $1.1 \mathrm{~V} \mathrm{vs.} \mathrm{SCE} \mathrm{for} 60 \mathrm{~s}$ on the Pt disc electrode surface. Also, the thickness of PEDOT/MWCNTs/AO composite films was controlled by the total charge passing through the cell, which was read directly from the current-time curves by computer. The enzyme electrode was washed repeatedly with double-distilled deionized water to remove any loosely bound enzyme, the electrolyte and monomer from the electrode surface, and then stored in $0.05 \mathrm{M} \mathrm{PBS}(\mathrm{pH} 6.5)$ in a refrigerator $\left(4^{\circ} \mathrm{C}\right)$ when not in use. The fabrication procedure of the biosensor is schematically illustrated in Scheme 1.

\section{Amperometric biosensor measurements}

The amperometric detection of AA was carried out by applying a potential of $0.4 \mathrm{~V} v s$. SCE for $100 \mathrm{~s}$. The supporting electrolyte was $0.05 \mathrm{M}$ air-saturated PBS (pH 6.5). Each experiment was repeated three times at three sample cells with a constant concentration of AA, respectively, and each data point represented the average of data collected three times.

\section{Results and Discussion}

\section{The mechanism of AA determination}

In the present work, the amperometry technique was used to measure AA. AO was used to catalyze the oxidation of AA to L-dehydroascorbic acid (DHA) and water with the oxygen present in solution (illustrated in Scheme 1). The biocatalytical process for the oxidation of AA can be summarized as the following reaction:

$$
2 \mathrm{AA}+\mathrm{O}_{2} \stackrel{\mathrm{AO}}{\longrightarrow} 2 \mathrm{DHA}+2 \mathrm{H}_{2} \mathrm{O}
$$




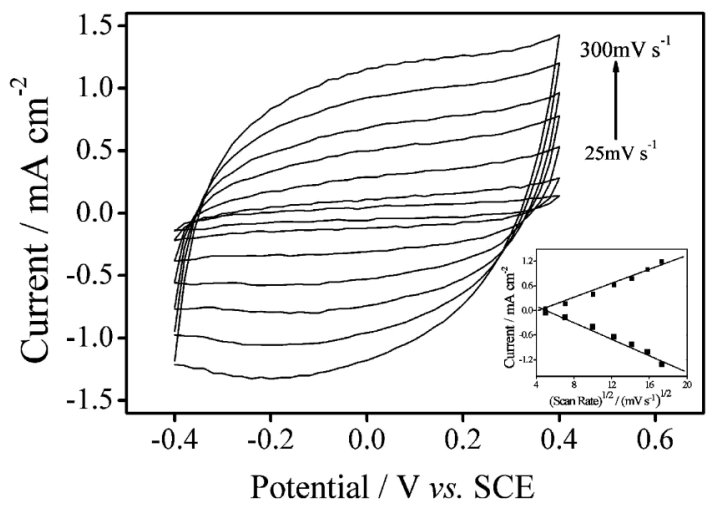

Fig. 1 Cyclic voltammograms of the PEDOT/MWCNTs/AO-modified electrode in $0.05 \mathrm{M}$ PBS (pH 6.5) containing $0.02 \mathrm{M} \mathrm{LiClO}_{4}$ at scan rates of $25,50,100,150,200,250$, and $300 \mathrm{mV} \mathrm{s}^{-1}$. The inset shows a calibration plot of the peak currents $v s$. the square of root of scan rate.

This reaction was denoted as a double-displacement reaction mechanism, ${ }^{32,33}$ which is a two-substrate reaction mechanism, two compound reactants $\mathrm{AA}$ and $\mathrm{O}_{2}$ resulting in products of DHA and $\mathrm{H}_{2} \mathrm{O}$. Substrates appear to bounce on and off the enzyme just like a ping-pong ball bouncing up and down on a table; thus, the mechanism is also called the "Ping-Pong" reaction mechanism. This is caused by a nucleophilic attack of one group onto another, followed by the release of another group to form a different compound. The double-displacement reaction does not occur sequentially; AA first binds to the free enzyme $\mathrm{AO}_{\text {ox }}$ (oxidized $\mathrm{AO}$ ) and forms $\mathrm{AA} \cdot \mathrm{AO}_{\text {ox }}$, then transforms into $\mathrm{AO}_{\text {red }}$ (reduced $\mathrm{AO}$ ). $\mathrm{DHA}$, next releases the product DHA and forms a modifying enzyme, $\mathrm{AO}_{\text {red }}$. The second substrate, $\mathrm{O}_{2}$ also binds to modifying the enzyme $\mathrm{AO}_{\text {red }}$ to form $\mathrm{O}_{2} \cdot \mathrm{AO}_{\text {red, }}$ which transforms into $\mathrm{AO}_{\mathrm{ox}} \cdot \mathrm{H}_{2} \mathrm{O}$, then releases another product $\mathrm{H}_{2} \mathrm{O}$ and forms the free enzyme $\mathrm{AO}_{\text {ox }}$ again. In the $\mathrm{AA}$ and $\mathrm{O}_{2}$ reaction catalyzed by $\mathrm{AO}$, the concentration of $\mathrm{O}_{2}$ was held constant, whereas AA varied in the as-obtained electrochemical biosensor. Therefore, freshly prepared sample solutions with different concentrations of AA were used prior to each measurement. Thusly, the concentration of $\mathrm{O}_{2}$ was kept constant in air-saturated PBS in all experiments.

\section{Cyclic voltammograms of the PEDOT/MWCNTS/AO-modified electrode}

Cyclic voltammetry was used to characterize the electrochemical behavior of the PEDOT/MWCNTs/AO-modified electrode. Figure 1 depicts cyclic voltammograms of the modified electrode in $0.05 \mathrm{M}$ PBS containing $0.02 \mathrm{M} \mathrm{LiClO}_{4}$ with the scan rate from 25 to $300 \mathrm{mV} \mathrm{s}^{-1}$. The PEDOT/MWCNTs/AO composite films could be cycled repeatedly without any obvious decomposition, which indicated that the composite films had good redox activity and stability. In addition, the peak currents $v s$. the square of root of scan rate exhibited a linear relationship, which suggested a diffusion-controlled process.

As is well known, the active center of AO is deeply embedded in a protective protein shell, which makes direct electron transfer between the enzymes and the electrodes extremely difficult. An important feature for the immobilized enzyme electrode lies in that the active immobilization matrix can improve the electron-transfer ability between the enzyme and the electrode surface. Therefore, the electrochemical performance of the immobilized enzyme electrode is largely dependent on the electrochemical properties of the active immobilization matrix on the electrode. In our previous work, we proved that the

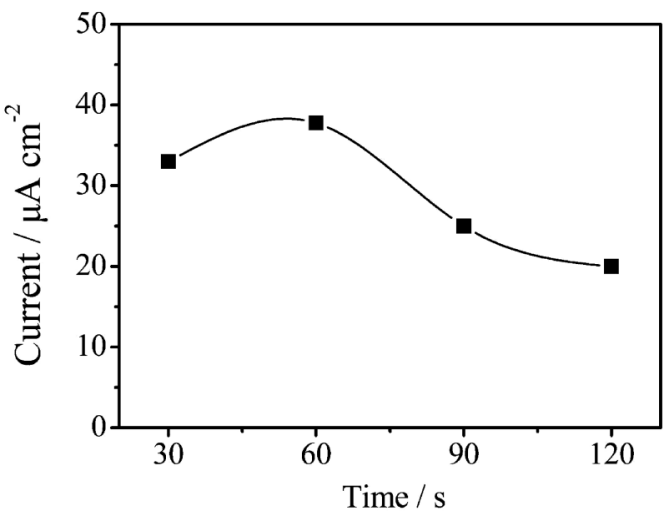

Fig. 2 Effect of the electropolymerization time on the biosensor response in $0.5 \mathrm{M}$ PBS (pH 6.5) containing $0.5 \mathrm{mM} \mathrm{AA}$ at $25^{\circ} \mathrm{C}$. Applied potential, $0.4 \mathrm{~V}$.

PEDOT/MWCNTs composite films showed better electrochemical activity compared with pure PEDOT films. ${ }^{34}$ MWCNTs can form a network and project outward from the electrode, acting like bundled ultramicroelectrodes that permit access to the active sites of enzymes, facilitating direct electron transfer, which may improve electrochemical performance of the PEDOT/MWCNTs-based biosensor. ${ }^{35,36}$

\section{Optimization of experimental conditions}

To improve the performance of the biosensor, various factors influencing the response of the biosensor, such as the film thickness, $\mathrm{pH}$ of the detection solution, applied potential used in the determination and temperature were investigated in detail.

Normally, the thickness of the PEDOT/MWCNTs/AO composite films defines the response of an enzyme-based biosensor. The electrodeposition time plays an important role in the thickness of the deposited PEDOT/MWCNTs/AO composite films. In this study, the composite films were electrodeposited on the electrode by the potentiostatic method. The effect of the amount of deposited films on the response current of the biosensor was investigated (Fig. 2). The response current of the PEDOT/MWCNTs/AO-modified electrode to $0.5 \mathrm{mM}$ AA increased with an increase of the electrodeposition time from 30 to $60 \mathrm{~s}$. However, when the electrodeposition time was more than $60 \mathrm{~s}$, the response current gradually decreased, which indicated the thickness increase of the polymer, the obstacle of electron-transfer. Besides, a longer deposition time would result in a longer response time. Therefore, the deposition time of $60 \mathrm{~s}$ was selected in a following investigation.

The response of the AA biosensor depends on the activity of immobilized $\mathrm{AO}$, which is associated with the $\mathrm{pH}$ of the ambient environment. The effect of the $\mathrm{pH}$ on the performance of the biosensor was studied in PBS with different $\mathrm{pH}$ values $(5-8)$ when the biosensor was subject to $0.5 \mathrm{mM}$ AA standards, as shown in Fig. 3. The current gradually increased from pH 5.0 to 6.2 , and after achieving the maximum current at around $\mathrm{pH} 6.2$, it decreased, indicating that the optimum activity occurred at around $\mathrm{pH} 6.2$.

The effect of varying the temperature on the biosensor response was also examined between 20 and $50^{\circ} \mathrm{C}$. As illustrated in Fig. 4, the current response increased progressively with an increase in temperature, reaching a maximum response current at about $40^{\circ} \mathrm{C}$, and then decreased sharply. This could be caused by the denaturation of $\mathrm{AO}$ at higher temperatures. Although the biosensor showed a maximum response at about $40^{\circ} \mathrm{C}$, room temperature $\left(25^{\circ} \mathrm{C}\right)$ was still chosen for this work in 


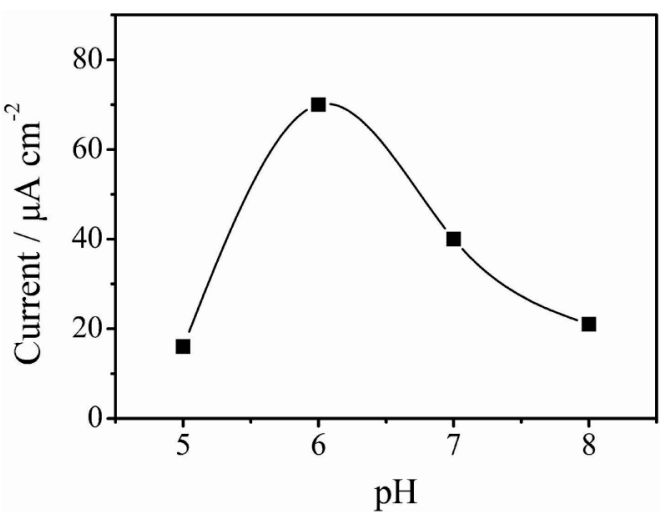

Fig. 3 Effect of the $\mathrm{pH}$ on the biosensor response in PBS containing $0.5 \mathrm{mM} \mathrm{AA}$ at $25^{\circ} \mathrm{C}$. Applied potential, $0.4 \mathrm{~V}$.

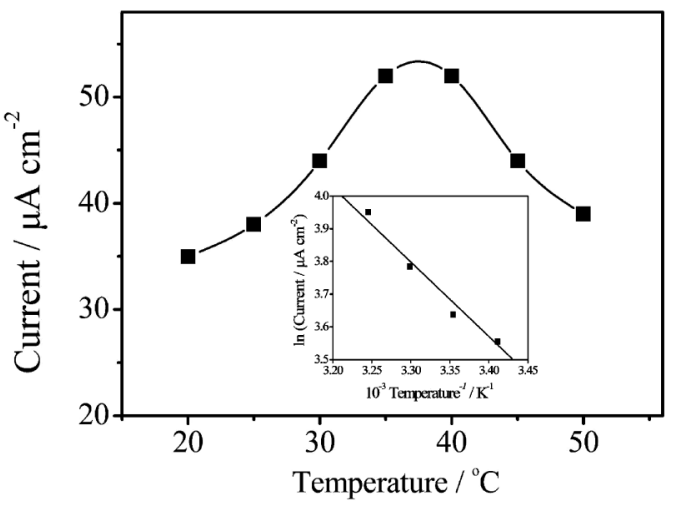

Fig. 4 Effect of the temperature on the biosensor response in PBS (pH 6.5) containing $0.5 \mathrm{mM}$ AA. Applied potential, $0.4 \mathrm{~V}$; inset, plot of the $\ln I v s . T^{-1}$.

order to keep the stability of the biosensor and to prevent possible solution evaporation at higher temperature.

The dependence of the response current on the temperature in an initial region can be expressed as an Arrhenius relationship, ${ }^{37,38}$

$$
I(T)=I_{0} \exp \left(\frac{-E_{\mathrm{a}}}{R T}\right)
$$

Here, $I$ represents the steady-state current response, $I_{0}$ represents a collection of currents, $R$ is the universal gas constant, $T$ is the absolute temperature in Kelvin and $E_{\mathrm{a}}$ is the apparent activation energy. The activation energy for an enzymatic reaction could be calculated according to the slope of the plots of $\ln I-1 / T$ in the range of $20-35^{\circ} \mathrm{C}$ (inset of Fig. 4). Thus, an estimated value for $E_{\mathrm{a}}$ of $21 \mathrm{~kJ} \mathrm{~mol}^{-1}$ was obtained for the AO-catalyzed reaction. This $E_{\mathrm{a}}$ value was smaller than that $\left(43.496 \mathrm{~kJ} \mathrm{~mol}^{-1}\right)$ reported for AO immobilized in PEDOT film. ${ }^{31}$ This smaller $E_{\mathrm{a}}$ value means that the $\mathrm{AO}$ immobilized in PEDOT/MWCNTs composite films possesses higher enzymatic activity.

The effect of the applied potential on the amperometric response of the PEDOT/MWCNTs biosensor was studied, as shown in Fig. 5. The amperometric current response for AA increased as the applied potential increased from 0 to $0.4 \mathrm{~V}$. The maximum response was attained at $0.4 \mathrm{~V}$, and the application of a more positive potential up to $0.5 \mathrm{~V}$ did not improve the current response. Thus, $0.4 \mathrm{~V}$ was chosen as the optimal potential for the amperometric detection of AA.

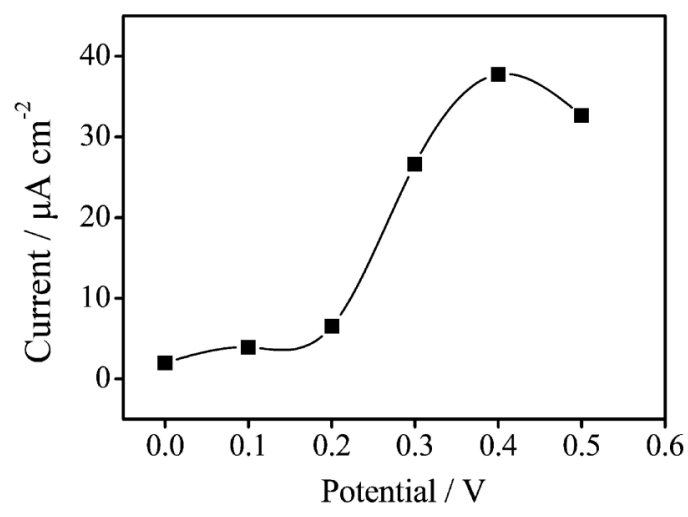

Fig. 5 Effect of the applied potential on the biosensor response in PBS ( $\mathrm{pH} 6.5$ ) containing $0.5 \mathrm{mM}$ AA at $25^{\circ} \mathrm{C}$.

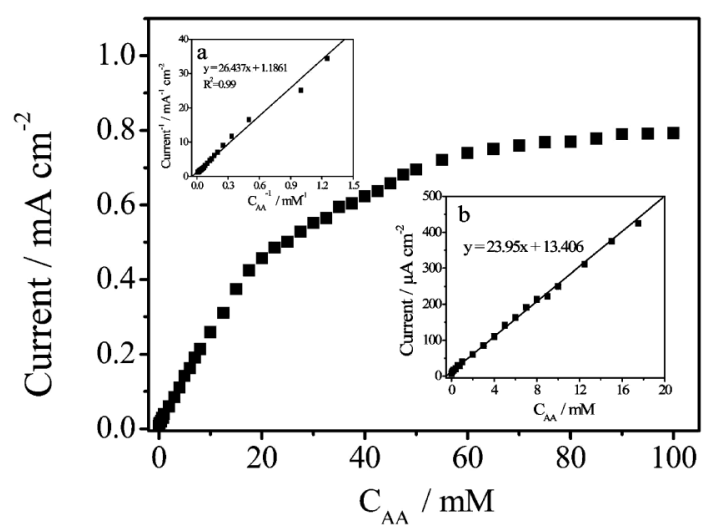

Fig. 6 Relationship between the response current and the concentration of AA in $0.05 \mathrm{M}$ PBS ( $\mathrm{pH} 6.5)$ at $25^{\circ} \mathrm{C}$. Applied potential, $0.4 \mathrm{~V}$. Inset (a) shows the determination of the apparent Michaelis-Menten constant; inset (b) is the calibration curve for the biosensor response $v s$. different concentrations of AA.

Amperometric response of the biosensor and calibration curve

Amperometric AA measurements were performed with the prepared biosensor at a fixed working potential $(0.4 \mathrm{~V})$ in PBS containing different AA concentrations (0 to $100 \mathrm{mM})$, represented in Fig. 6. The concentration of $\mathrm{O}_{2}$ was kept constant in air-saturated PBS, because $\mathrm{O}_{2}$ was a co-substrate of the $\mathrm{AO}$ reaction. The steady-state currents gradually increased with increasing concentration of AA, and exhibited a linear relationship with the concentration of AA in the range from 0.05 to $20 \mathrm{mM}$ with a detection limit of $15 \mu \mathrm{M}$ (estimated at $S / N=3$ ) with a correlation coefficient of 0.99 . The sensitivity (determined from the slope of the initial linear part of the calibration) is $23.95 \mathrm{~mA} \mathrm{M}^{-1} \mathrm{~cm}^{-2}$. It was observed that the biosensor response gradually deviated from the linear feature as the AA concentration up to $20 \mathrm{mM}$. This is the characteristic of a typical Michaelis-Menten kinetics. The apparent Michaelis-Menten constant, $K_{\mathrm{m}}$, which depicts the enzyme-substrate kinetics of the biosensor, can be calculated from the Lineweaver-Burk equation, ${ }^{39}$

$$
\frac{1}{I_{\mathrm{ss}}}=\left(\frac{K_{\mathrm{m}}}{I_{\max }}\right)\left(\frac{1}{C}\right)+\frac{1}{I_{\max }},
$$

where $I_{\mathrm{ss}}$ is the steady-state current, $C$ the concentration of AA, 
Table 1 Performances of the fabricated AA biosensor compared to the reported biosensors

\begin{tabular}{|c|c|c|c|c|c|}
\hline Property & Present & Wen et al..$^{31}$ & Chauhan et al. ${ }^{40}$ & Akyilmaz et al..$^{41}$ & Wang et al..$^{42}$ \\
\hline Support for immobilization & PEDOT/MWCNTs & PEDOT & Egg shell membrane & Teflon membrane & Polystyrene \\
\hline Method of immobilization & Entrapment & Entrapment & Covalent coupling & Adsorption & Adsorption \\
\hline Mode of measurement & Current & Current & Current & Current & Dissolved $\mathrm{O}_{2}$ \\
\hline Response time & $20 \mathrm{~s}$ & $30 \mathrm{~s}$ & $10 \mathrm{~s}$ & $45 \mathrm{~s}$ & Within $1 \mathrm{~min}$ \\
\hline Detection limit & $15 \mu \mathrm{M}$ & $33 \mu \mathrm{M}$ & $10 \mu \mathrm{M}$ & $\begin{array}{c}5.0 \times 10^{-5} \text { and } \\
1.2 \times 10^{-3} \mathrm{M}\end{array}$ & $2-4 \mu \mathrm{M}$ \\
\hline Range/M & $0.5 \times 10^{-4}-2 \times 10^{-2}$ & $1 \times 10^{-4}-1 \times 10^{-2}$ & $1 \times 10^{-5}-4 \times 10^{-4}$ & $4.0 \times 10^{-4}-1 \times 10^{-3}$ & $1 \times 10^{-6}-4 \times 10^{-4}$ \\
\hline Storage stability & $\begin{array}{l}\text { Retained } 99 \% \text { of its } \\
\text { initial activity after } \\
10 \text { days and retained } \\
60 \% \text { after } 30 \text { days }\end{array}$ & $\begin{array}{l}\text { Retained } 88 \% \text { of its } \\
\text { initial activity after } \\
6 \text { days and retained } \\
58 \% \text { after } 12 \text { days }\end{array}$ & $\begin{array}{l}\text { Maintained } 50 \% \text { of } \\
\text { its initial activity } \\
\text { after } 120 \text { days }\end{array}$ & $\begin{array}{l}\text { Retained } 85 \% \text { of its } \\
\text { initial activity after } \\
60 \text { days }\end{array}$ & $\begin{array}{l}\text { Retained } 60 \% \text { of its } \\
\text { initial activity after } \\
14 \text { days }\end{array}$ \\
\hline
\end{tabular}

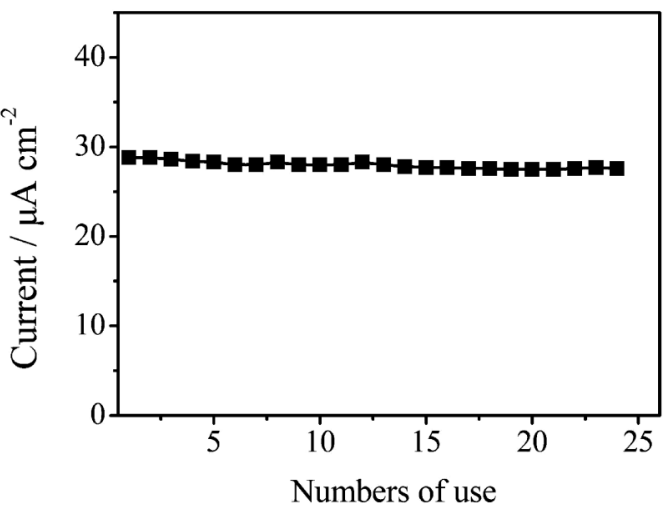

Fig. 7 Reproducibility of the PEDOT/MWCNTs/AO-modified electrode.

$K_{\mathrm{m}}$ the apparent Michaelis-Menten constant and $I_{\max }$ the maximum current. From the curve of $I_{\mathrm{ss}}{ }^{-1} v s$. $C^{-1}$, based on the experimental data from Fig. 6, the apparent Michaelis-Menten constant, $K_{\mathrm{m}}$, was estimated to be $19.5 \mathrm{mM}$.

The analytical performance of the constructed biosensor was compared with those of other AA biosensors (Table 1). From the date presented in Table 1, it could be observed that the AA biosensor in our work was characterized by a wider linear range, lower detection limit and better storage stability compared with the pure PEDOT-based biosensor prepared with the similar method, which may benefit from the synergistic activity between PEDOT and MWCNTs.

Reproducibility and storage stability studies of AA biosensor

The operational stability of the biosensor for AA was determined with 24 repetitive experiments by using the same enzyme electrode. At the end of the 24th experiment for AA, the biosensor retained $97 \%$ of its original activity. The reproducibility of the enzyme electrode is given in Fig. 7. The satisfying result demonstrated that a small amount of enzyme was leaked out, which indicates the good reproducibility of the PEDOT/MWCNTs/AO-modified electrode.

The storage stability is an extremely important parameter to be considered for a biosensor. The storage stability of the AA biosensor was examined by intermittently measuring the current response to an AA standard solution every 3 days over a period of one month (Fig. 8a). The amperometric response of the biosensor remained at $99 \%$ of its initial activity for the first 10 days, and $65 \%$ activity was retained after one month. The good storage stability of the biosensor could be attributed to the biocompatible environment of PEDOT and the strong sorption

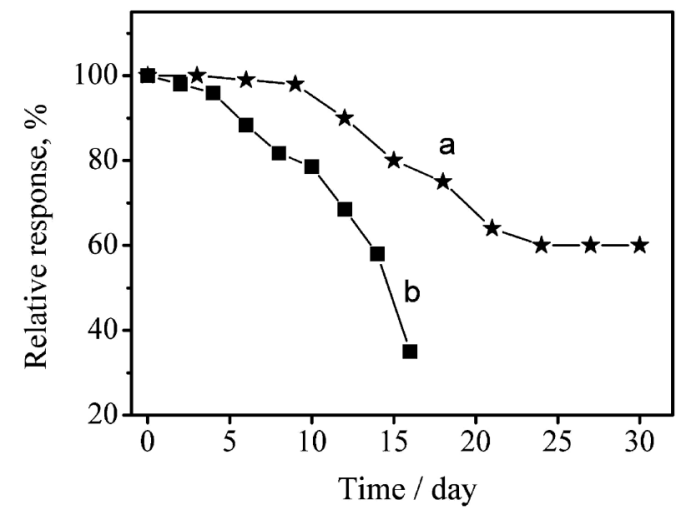

Fig. 8 Storage stability of (a) PEDOT/MWCNTs/AO-modified electrode, (b) PEDOT/AO-modified electrode.

capability of MWCNTs. For a comparison, the storage stability of the PEDOT/AO-modified electrode was also investigated (Fig. 8b), by intermittently measuring the current response to the AA standard solution every 2 days over a period of two weeks. During the first 2 days, the current response had about $5 \%$ decreasing, and in the next 2 weeks the current response decreased sharply by about $65 \%$ of its initial activity. It can be seen that the PEDOT/MWCNTs/AO-modified electrode in our work had a better storage stability than the PEDOT/AO-modified electrode. There are two reasons for this good storage stability. First, the PEDOT/MWCNTs composite films on the electrode surface were very stable. Second, the three-dimensional network structure of the PEDOT/MWCNTs composite could provide a biocompatible microenvironment for maintaining the native activity of the enzyme, and preventing its possible leakage from the electrode surface.

\section{Interference test}

The effects of the interference of a variety of compounds (fructose, glucose, sucrose, citric acid, L-alanine, ethanol, sodium chloride, oxalic acid, inositol and nicotinic acid) in monitoring AA was also investigated. Only L-alanine decreased the sensor response by $15 \%$, while others had no obvious effect on the amperometric response (Table 2). Thus, the biosensor exhibits good anti-interferent ability.

\section{Conclusions}

In this paper, an amperometric AA biosensor was firstly fabricated by immobilizing AO in PEDOT/MWCNTs composite 
Table 2 Influence of the electroactive interferents of the AA response

\begin{tabular}{|c|c|c|}
\hline \multirow[b]{2}{*}{ Interferent } & \multicolumn{2}{|c|}{ Relative activity, \% } \\
\hline & $\begin{array}{c}\text { Interferent } \\
\text { concentration, } \\
0.5 \mathrm{mM}(\mathrm{AA} 0.5 \mathrm{mM})\end{array}$ & $\begin{array}{c}\text { Interferent } \\
\text { concentration, } \\
1 \mathrm{mM}(\mathrm{AA} 0.5 \mathrm{mM})\end{array}$ \\
\hline Fructose & 100 & 100 \\
\hline Glucose & 100 & 100 \\
\hline Sucrose & 100 & 100 \\
\hline Citric acid & 100 & 100 \\
\hline L-Alanine & 85 & 85 \\
\hline Ethanol & 100 & 100 \\
\hline Sodium chloride & 100 & 100 \\
\hline Oxalic acid & 100 & 100 \\
\hline Inositol & 100 & 100 \\
\hline Nicotinic acid & 100 & 100 \\
\hline
\end{tabular}

films using the one-step electrochemical polymerization method. Subsequently, the optimal experimental conditions of the AA biosensor were studied in detail, such as the film thickness, $\mathrm{pH}$ value, detection potential and temperature. The AA biosensor could determine the concentration of AA successfully, and showed superior performance, such as wide linear range, fast response time, low detection limit and good reproducibility by combining the merits of PEDOT and MWCNTs. Moreover, the biosensor displays a good anti-interferent ability and excellent storage stability. Hence, our work proves that the PEDOT/MWCNTs composite material is a promising enzyme immobilization platform for fabricating enzyme-based biosensors. All of these advantages are also suitable for practical applications in the agro-industry.

\section{Acknowledgements}

NSFC (50963002, 51073074), Key Projects in the National Science \& Technology Pillar Program in the Eleventh Five-year Plan Period (2006BAD02A04, 2006BAD01A01), Key Laboratory of Photochemical Conversion and Optoelectronic Materials, TIPC, CAS, Jiangxi Provincial Department of Science and Technology (2006BAD01A01-2-5), Jiangxi Provincial Department of Education (GJJ11590), Natural Science Foundation of Jiangxi Province (2010GZH0041), and Jiangxi Provincial Innovation Fund of Postgraduates (YC10A063) are acknowledged for their financial support.

\section{References}

1. P. Lopes, J. Drinkine, C. Sacier, and Y. Glories, Anal. Chim. Acta, 2006, 555, 242.

2. Y. Hernandez, M. G. Lobo, and M. Gonzalez, Food Chem., 2006, 96, 654.

3. B. Tang, M. Wang, J. Du, Z. Ge, and J. Chen, J. Agric. Food Chem., 2003, 51, 4198.

4. Y. Andreu, S. D. Marcos, J. R. Castillo, and J. Galben, Talanta, 2005, 65, 1045.

5. V. S. Ijeri, M. Algarra, and A. Martins, Electroanalysis, 2004, 16, 2082.

6. Z. Bae, J. Park, S. Lee, and H. Chang, J. Electroanal. Chem., 1999, 468, 85.

7. E. Turkusic, V. Milicevic, and H. Tahmiscija, Fresenius $J$. Anal. Chem., 2000, 368, 466.

8. X. Wang, H. Watanabe, and S. Uchiyama, Talanta, 2008,
$74,1681$.

9. M. F. S. Teixeira, L. A. Ramos, O. Fatibello, and E. T. G. Cavalheiro, Anal. Bioanal. Chem., 2003, 376, 214.

10. S. V. Dzyadevych, V. N. Arkhypova, and A. P. Soldatkin, ITBM-RBM, 2008, 29, 17.

11. I. D. H. C. Marques, E. T. A. Marques, A. C. Silva, and W. M. Ledingham, Appl. Biochem. Biotechnol., 1994, 44, 81.

12. R. M. Lanniello and A. M. Yacynych, Anal. Chem., 1981, 53, 2090.

13. Y. M. Lvov, Z. Lu, J. B. Schenkman, X. Zu, and J. F. Rusling, J. Am. Chem. Soc., 1998, 120, 4073.

14. M. F. Suaud-Chagny and F. G. Gonon, Anal. Chem., 1986, 58,412

15. T. Tatsuma, Y. Okawa, and T. Watanabe, Anal. Chem., 1989, 61, 2352.

16. M. Umana and J. Waller, Anal. Chem., 1986, 58, 2979.

17. T. Ahuja, I. A. Mir, and D. Kumar, Biomaterials, 2007, 28, 791.

18. D. D. Borole, U. R. Kapadi, and P. P. Mahulikar, Monomers Polym., 2006, 9, 1.

19. M. Gerard, A. Chaubey, and B. D. Malhotra, Biosens. Bioelectron., 2002, 17, 345.

20. P. R. Unwin and A. J. Bard, Anal. Chem., 1992, 64, 113.

21. F. R. R. Teles and L. P. Fonseca, Mat. Sci. Eng. C, 2008, 8, 1530.

22. F. Wang, M. S. Wilson, R. D. Rauh, and P. Schottland, Macromolecules, 2000, 33, 2083.

23. L. B. Groenendaal, F. Jonas, D. Freitag, H. Pielartzik, and J. R. Reynolds, Adv. Mater., 2000, 7, 12.

24. J. J. Davis, M. L. H. Green, H. A. O. Hill, Y. C. Leung, P. J. Sadler, J. Sloan, A. V. Xavier, and S. C. Tsang, Inorg. Chim. Acta, 1998, 272, 261.

25. M. Wang, F. Zhao, Y. Liu, and S. Dong, Biosens. Bioelectron., 2005, 21, 159.

26. S. G. Wang, Q. Zhang, R. L. Wang, and S. F. Yoon, Electrochem. Commun., 2003, 5, 800.

27. X. L. Luo, A. J. Killard, A. Morrin, and M. R. Smyth, Anal. Chim. Acta, 2006, 575, 39.

28. M. M. Rahman, M. J. A. Shiddiky, M. A. Rahman, and Y. B. Shim, Anal. Biochem., 2009, 384, 159.

29. D. Du, X. X. Ye, J. Cai, J. Liu, and A. Zhang, Biosens. Bioelectron., 2010, 25, 2503.

30. J. Y. Chiu, C. M. Yu, M. J. Yen, and L. C. Chen, Biosens. Bioelectron., 2009, 24, 2015.

31. Y. P. Wen, B. Y. Lu, R. R. Yue, H. H. He, and J. K. Xu, Talanta, unpublished results.

32. A. G. Marangoni, "Enzyme Kinetics: A Modern Approach", 2003, John Wiley and Sons, New York, NJ.

33. T. Nakamura, N. Makino, and Y. Ogura, J. Biochem., 1968, 64, 189.

34. M. Liu, Y. P. Wen, D. Li, H. H. He, and J. K. Xu, J. Appl. Polym. Sci., in press.

35. J.-F. Rochette, E. Sacher, M. Meunier, and J. H. T. Luong, Anal. Biochem., 2005, 336, 305.

36. G-E. Anthony, C. Lei, and R. H. Baughman, Nanotechnology, 2002, 13, 559.

37. S. Cosnier, S. Szunerits, R. S. Marks, A. Novoa, L. Puech, and E. Perez, Talanta, 2001, 55, 889.

38. D. Shan, M. Zhu, and S. Xue, Biosens. Bioelectron., 2007, 22, 1612 .

39. R. A. Kamin and G. S. Wilson, Anal. Chem., 1980, 52, 1198.

40. N. Chauhan, T. Dahiya, Priyanka, and C. S. Pundir, J. Mol. Catal. B: Enzym., 2010, 67, 66.

41. E. Akyilmaz and E. Dinckaya, Talanta, 1999, 50, 87.

42. X. Y. Wang, H. Watanabe, and S. Uchiyama, Talanta, 2008, 74,1681 . 